\title{
||||||||||||||||||||||||||||||||||||||||||||||||||||||||||||||||||||.
}

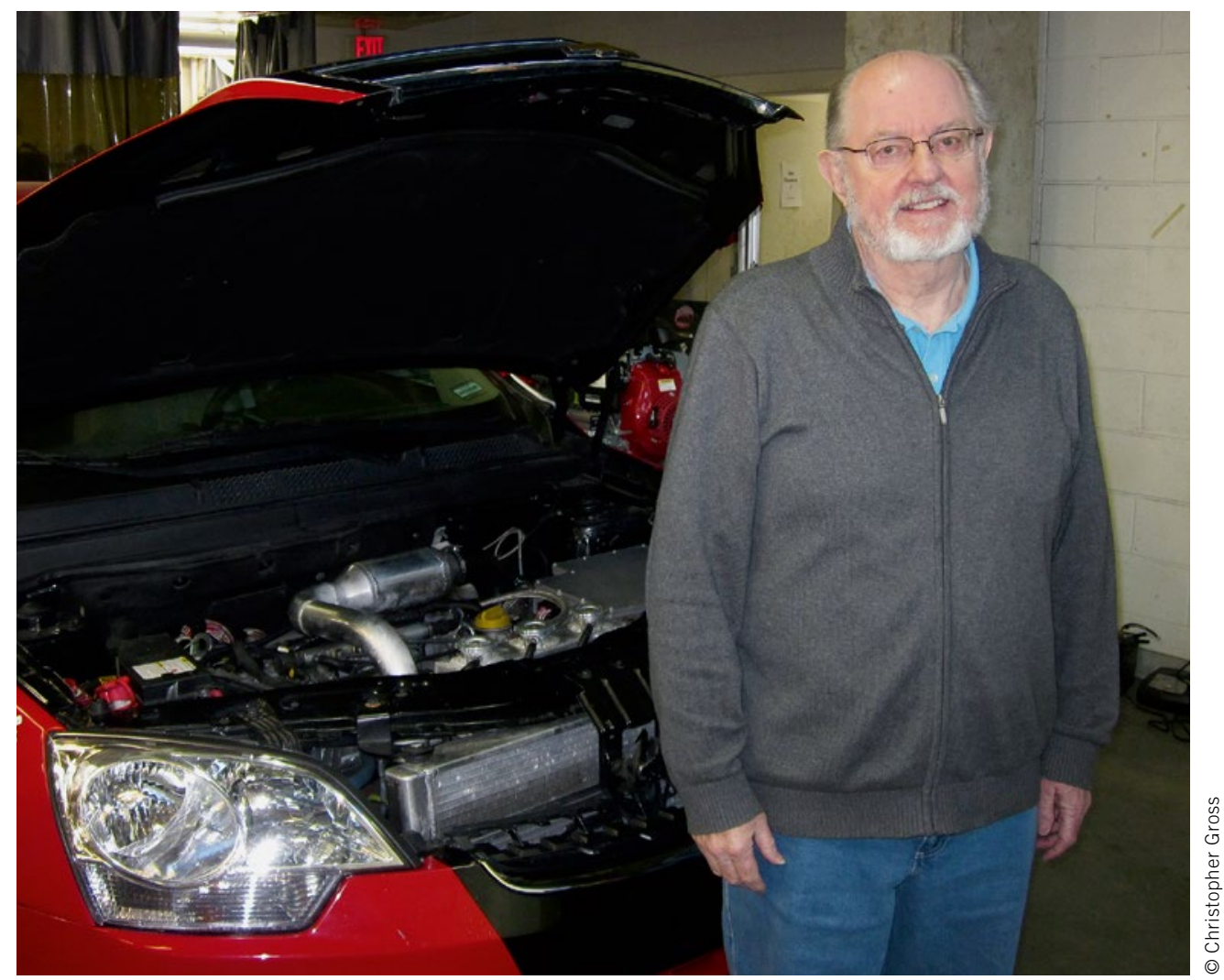

Rolf D. Reitz

Professor Emeritus of Mechanical Engineering at Engine Research

Center, University of

Wisconsin-Madison (USA)

\section{The Diesel Dilemma}

Prospects for replacing the IC engine with more efficient and cleaner power plants are not hopeful. Indeed, the National Research Council concluded that: “...the internal combustion engine (ICE) will be the dominant prime mover for light-duty vehicles for many years, probably decades." Also, there is no obvious alternative to the IC engine for medium- and heavyduty commercial vehicles, which account for a quarter of all fuel used (mostly diesel). However, the fuel used by IC engines has a major impact on our global environment. Burning $1 \mathrm{~kg}$ of fuel generates about $3 \mathrm{~kg}$ of $\mathrm{CO}_{2}$, a major Green House Gas (GHG). As climate negotiators in Paris discuss GHG reductions, the cheating scandal at Volkswagen has raised questions about the survival of the diesel engine, long considered a key to increasing fuel efficiency and reducing carbon emissions. VW cars released up to 40 times the US Environmental Protection Agency's permissible level of nitrogen oxides, an asthma trigger. This highlights the diesel engine's dilemma: diesels trade pollution for great mileage. So, why is the survival of the diesel on the line? If VW's engineers cannot meet pollution and mileage standards today, what will happen in 2017 when California, the air-quality trend-setter, enacts its planned 10 -fold tightening of nitrogen oxide limits?
Fortunately, there have been significant technological advances that address the diesel dilemma. Delphi Automotive, for example, is developing Gasoline Compression Ignition (GCI), which uses gasoline in a diesel engine, giving diesel-like efficiencies and low emissions. GCI relies on the relatively long ignition delay times of gasoline that allow the fuel and air to mix in the engine before combustion. However, GCI works best with very low octane fuels (currently not widely available), and has trouble starting and operating at low loads. At the Engine Research Center, we are developing a technology we call Reactivity Controlled Compression Ignition (RCCI) that uses both gasoline and diesel to solve the diesel dilemma. Controlled injections of small amounts of the more reactive diesel fuel promote the ignition of port-injected gasoline. Using this combination of fuels, we have achieved efficiencies that rival the best efficiencies in history. Depending on size, our test engines convert between 50 and $60 \%$ of fuel energy into work. RCCI's patented technology satisfies economy and pollution goals by retaining each fuel's key benefit, varying the fuel mixture on the fly to meet changing driving conditions. With the diesel engine in dire straits, there could not be a better time for research into promising solutions to the diesel dilemma. 